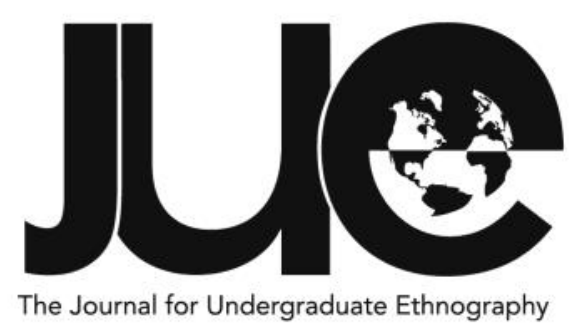

\title{
Liminal Social and Physical Spaces: Aspects of Identity and Socialization Patterns in a Neighborhood House
}

\section{Alannah Berson}

University of British Colombia, a.berson@alumni.ubc.ca

\section{ABSTRACT}

Vancouver, British Columbia, is a changing city with a diverse population from all over the globe. Within this metropolis are small neighborhood houses where people can find community services like conversation groups to learn English, clubs to meet new people, and daycare and preschool to care for their children. This article explores social relations in one neighborhood house. Despite the small size of the house, the members and users of the house do not necessarily identify with a larger house identity or an imagined community. Using ethnographic research, this paper examines how gentrification, imagined communities, and liminal events separate and unite different portions of the house membership via Goffmanian theory about masks, teams, and regions. It looks at the house in terms of individuals establishing team identity through space-claiming practices that reinforce mask identities. In a place and time of demographic change, this paper seeks to find out how the concept of neighbors and neighborhood membership is changing through individual and group efforts to control shared spaces. 
G entrification and radical changes in neighborhood demographics are frequent conversations throughout Vancouver, British Columbia, as the thirdlargest Canadian city continues to have a notoriously tight housing market and a long history of immigrant neighborhoods. Mountain Neighborhood House is situated towards the southern end of the city. The house is part of a citywide system of non-profit "neighborhood houses," sites for community programs to give people a place to socialize or get support. As such, it is at the forefront of helping diverse sections of the neighborhood population through a variety of services. As the surrounding area undergoes gentrification, the house continues to focus on reaching out to low-income and new immigrant families, while also offering daycare to those lucky few who can afford it and can get one of the limited spaces. In this article, I examine how the various populations served by the neighborhood house seek space in the house and create and navigate various interactional identities bounded by events. Members of the house create imagined communities via participating in events at the house, which create interactional teams that depend on the liminality or in-betweenness of the house to bring together people otherwise separated by stages of gentrification.

\section{The Neighborhood}

The Mountain neighborhood is about a 30 minute bus ride from the downtown core of Vancouver and, like the downtown, is undergoing development that is changing the faces of businesses and of residents, including gentrification. Gentrification has been the subject of much debate, but it can be understood as "a complex process, or set of processes, involving physical improvement of the housing stock, housing tenure change from renting to owning, price rises, and the displacement or replacement of the exiting working-class population by the middle classes" (Hamnett 2003, 331). The city has a recognized housing shortage that continually forces housing and rental prices up (Sutherland et al. 2014). Frequently, older buildings, apartments and houses are torn down and rebuilt with newer, more expensive versions of what was there before, displacing the previous residents, often students or immigrants. The ethnic food restaurants are giving way to expensive cafes and shops selling vintage clothing and local handicrafts. This creates an area that glorifies objects and activities from times past (Glass 1964), while restoring older buildings to newer ways of life to support various interpretations of artistic consumption (Zukin 2010). This follows a decade-long trend of low vacancy rates in Vancouver, a city push to create a "livable" space, and a broader shift in the economy to people being employed in sociocultural fields (Ley 2010). This area is the perfect illusion of a diverse artistic paradise; however, Vancouver rent prices are beyond the reach of most artists and there are only a few traces remaining of the immigrant culture that previously characterized the area.

Walking through the neighborhood revealed a noticeable difference in socialization patterns between the newer houses and freshly painted apartment buildings compared to the older or more rundown houses. Among the newer houses, not that many children play outside, and rarely do people spend much time talking to their neighbors over fences. Instead, people seem to focus on their own families more and there is little feeling of being united by anything other than geographic location. This pattern of outdoor sociability is similar to what Levy and Roman (2010) describe as hidden dimensions of culture and class. They suggest that people who move into an area as a result of gentrification often use outdoor spaces for specific activities, not for prolonged social engagements like older residents do (Levy and Roman 2010, 288). Such differences in lifestyle patterns can even lead to feelings of resentment between older and newer residents, based on different conceptions of work and play (Levy and Roman 2010, 289). While I was living in the 
neighborhood, my landlord warned me repeatedly about people hanging around in the area and there were a few times that I noticed a community police vehicle patrolling the area, creating an aura of fear and institutional intimidation that compelled people to adhere to the idea of spending time indoors unless going somewhere or engaged in a specific activity (Pérez 2010). Thus, the current concept of neighborhood in this area might be that of people sharing a geographical area and a belief that their neighbors are going though similar life styles and experiences, forsaking the imagined historical idea of "neighbors" being united through direct engagement with those who live nearby. This contrasts with the imaginary communities of Mountain Neighborhood House, where employees aim to facilitate neighbors engaging with other members of the house through various activities.

\section{Methods}

Given the changing patterns of socialization between neighbors as a result of gentrification, the neighborhood house is a primary socialization space, a space shared by the older and newer residents of the area. I spent six weeks volunteering in the Mountain Neighborhood House as part of an ethnography course, helping with various food and social programs. During this time, I observed and talked with staff and members of the house as they organized or accessed the diverse programming. Throughout my conversations and fieldnotes, as well as my interview with my supervisor, I noticed that discrete interactional spaces were created throughout the house. To analyze the creation of distinct social spaces in the house, I use the concept of "taming space," following Robertson (2007), to discuss how members navigate and claim physical space for themselves or their group. This navigation process depends on the formation of "teams" and "regions," as defined by Goffman (1959), as well as the "inbetweenness" or liminality (Turner 1967) of both the house and the teams, which creates temporary interactional sites that may reinforce or challenge team identities maintained outside of the house. Gentrification has fostered a transition between established patterns and residents and new ones, creating an in-between state in the process. Thus the neighborhood house acts as an interactional stage for the various identities and the creation of "imagined communities" (Anderson 1983) based on individuals' conception of their own and others' "neighborly" identities.

\section{The House}

I went to the neighborhood house to meet with my supervisor and get an idea of what programs the house offers and in which I would be involved. From the front door of the house, I walked past a few chairs to the left of the front desk and a set of small offices on the right. Staff normally shared each office with three or four other people. Beyond this entryway was a set of stairs on the left, more chairs and a fireplace just beyond that, and a daycare at the end of the hall. There was a kitchen to the right of the daycare, followed by two large rooms called East and West Hall on the right side of the hallway, along with some bathrooms. Most of the special events take place in the East and West Halls because they have a foldable dividing wall between them and are the largest rooms in the house. While the East Hall was empty when I first arrived, the West Hall was occupied by a Chinese seniors' conversational group learning English. The upstairs had a small glass-walled meeting room, a preschool, and three larger meeting rooms. There were more offices where staff again shared rooms with three or four other people.

When I met Brianna, my supervisor, she listed the variety of programs that the house offered: a daycare, a preschool, special events to encourage people to socialize, and settlement programs to inform recent immigrants about Canadian culture and help them learn English if necessary. My work at the house centered on helping in the kitchen during the special events, making a map of food assets in the area, such as low-cost or environmentally friendly food, and administering a survey about what programs people were using and whether they had suggestions for future programs. The survey was not created by me, was not part of this project, and continued after I had left, which meant that I did not have access to the results. The ensuing observations and 
reflections focus more on the process of administering the survey rather than the questions listed on it.

In the process of conducting the survey I spent time sitting on the first floor outside of the daycare, kitchen, and two main rooms. In the mornings and afternoons, parents in their 30s wearing suits, clean-cut spandex exercise wear, or fresh t-shirts and jeans would drop off their children at the daycare. Meanwhile, Asian seniors would occasionally sing in a Chinese choir in the East hall, or a Spanish play-group would gather in the West Hall. Even when the seniors saw the children on the way to the washroom, they would never acknowledge the children, just as the well-dressed parents rarely looked to the sides of the hallway as they dashed in with the forgotten lunch bag or walked and talked with their child on the way home for the day.

Despite sharing the same building in the neighborhood, and even the same open space of the hallway, it seemed like the different groups using the house did not interact with each other. However, when I was sitting in the chairs just off the hallway, I often found myself talking to staff, members, and anyone else who sat down for a moment. Sometimes the people were regulars, people who were almost always at the house, enjoying the coffee, waiting for a phone call, or waiting for the free bread given out on Fridays. Other times they were people who just wanted to drop in and visit with staff or other people who were frequently at the house. The chairs offered a place to sit and spend time without being in an activity, which might be why people tended to talk more here. While conducting the survey, I talked to a man who said he had spent almost a decade living in the area and that he liked coming to the house and doing various small jobs for the front desk, like changing light bulbs. He said that other times he just wanted to come in and sit down for a while. He was older, with grey hair, almost always wore a dusty embroidered cowboy shirt, and frequently joked with the woman who worked the front desk.

The boundaries of the patterns of sociability in the house simultaneously reinforce and contradict the patterns of taming space that Leslie Robertson (2007) describes in her discussion of the Vancouver Downtown Eastside (DTES). "Taming space," as Robertson defines it, consists of the "negotiations, transgressions and accommodations [people] make within particular spatial regimes" and the processes of how people reconcile their individual identities with wider social stereotypes of who occupies, works in, or passes through the area, each subject to their own stereotypes (Roberston 2007, 527). For some people, the Mountain neighborhood house acts as a social ground where they are accepted and given a safe place to enjoy free coffee, just as some of Robertson's interviewees find social recognition and acceptance for the first time in the DTES (Robertson 2007, 540). Women in the article talk about having space to call their own in the form of apartments (Robertson 2007, 544), or having a social space to have an identity accepted by a larger group (Robertson 2007, 539). Similarly, the Neighborhood House encouraged socializing among some members, but only within certain groups based on specific activities or services. Instead of strongly advertising the house as a place to spend periods of time, the flyers at the house stressed its services and did not mention its free coffee and chairs. Like Ho's (2015) account of a nearby neighborhood house, the free coffee and focused efforts of staff created a welcoming atmosphere for members but, in the Mountain Neighborhood House, group membership was enforced by participation in events or services used. For instance, the choir singers stuck together and did not talk to the people on the couches, the daycare parents, or the people in the room next door. This is an instance of taming space, of a room in the house being temporarily claimed as a place of identity based on an activity being scheduled there. However, part of this taming process is simply the negotiation of linguistic and other communicative divides between various groups within the space.

In addition to linguistic challenges in communicating in a multilingual area, there were activity-based barriers, as different activities encouraged groups to form around the activity. Goffman defines a performance team as "any set of individuals who co-operate in staging a single routine" (Goffman 1959, 79). The various purposes for which people use the 
house operate as "routines" that guide how people present themselves and think of others. These teams then act in "regions" of the house that bind people's perceptions of themselves, the house, and others in the house (Goffman 1959, 106). Goffman defines a region as "any place that is bounded to some degree by barriers to perception" (Goffman 1959, 106). The various areas of the house function as a source of identity, offering people a sense of purpose for being there, whether to socialize or to participate in a particular program. The "barriers to perception" can thus be walls within the house, activities that direct the focus of participants away from other occurrences in the house, and so on. In acting like a team, people lose some aspects of their individual identities as they seek to perform their task, making it difficult to interact with others outside of the group. The focus of such teams in turn claims some physical space within the house, making it a temporary region of team-based identity. Such identity performances focus on "express [ing] the characteristics of the task that is performed and not the characteristics of the performer" (Goffman 1959, 77). The house is thus broken down, socially and physically, into the various ways and reasons that people use the house, ensuring that groups of people with similar backgrounds and desires meet and socialize. Interacting with individuals from other groups is not discouraged, but neither is it encouraged.

Pamphlets and activities at the house frequently focused on different subgroups of the population, such as Mandarin or Cantonese speakers, Spanish parents, or parents needing childcare. With the focus on recent immigrants and the number of language related programs, it could be that people using one service do not communicate with people using another service for lack of a common language. Either way, people could identify as members of the same organization, and neighbors, yet avoid actually interacting with other members. The concept of "team" as defined by Goffman can thus be understood as operating at a few levels and styles of connection within the neighborhood house: the level of group activities for a range of audiences, that of the members of the house, and that of the wider neighborhood.
Regions and teams are not necessarily the same thing, but the concept of a neighborhood house depends on the group identity of "neighbors" where the shared task is living in some sort of communal way. Teams in this context are formed by performances of identity which inhabit particular regions of the house and wider neighborhood for varying periods of time. In the house, there are some regions that are very slow to change, like the daycare area or the kitchen, where set activities always occur, but there are other areas that change more rapidly, like the larger communal areas where different events are held on a daily basis. The wider neighborhood's patterns of gentrification are similar. There are some regions that change more rapidly and whose barriers to perception change who is included or excluded at faster rates than some local area stores and houses which hold on to their barriers longer. The sense of community depends on the vibe of the neighborhood, and how it is defined and enacted depends on how various waves of neighbors interpret "neighborly" behavior.

\section{Helping at Special Events}

While I was at the house I worked in the kitchen during a Cooking Club meeting and a Multicultural Dinner. Both events were based around being sociable over dinner, but were different sizes and had different target audiences. The Cooking Club is about 20 to 30 people who get together every two months or so and, led by a rotating volunteer cook, prepare food from different regions. The participants ranged in age and background. Some were young couples who had just moved to Canada, others were in their 40s and 50s and used the event as a chance to catch up with friends they had met in other programs run by the house. The event filled the kitchen with laughter, mostly English conversation, and spicy -smelling chicken.

The Multicultural Dinner was a much larger event with almost 100 people participating from the community and different programs in the house, a choir performing, and formal decorations. The kitchen was led by two Spanish-speaking women and some other volunteers, a few of whom were also members of the Cooking Club. Most of the cooking 
instructions and conversations were conducted in Spanish mixed with a bit of English because there were a number of Spanish-speaking volunteers and one cook who did not speak much English. However, not all of the volunteers spoke Spanish; two women spoke Mandarin or Cantonese as their first language, English as their second, and no Spanish. These women came to help prepare the food and ended up working with me preparing the rice, separately from the rest of the food preparation. When the food was served, the volunteers brought it out to the attendees who had bought tickets - and then we ate in a different portion of the house, away from the performing choir.

The two events seem quite similar in that they both focus on serving food in a social setting, but the exact bounds of where and when in the meal process the socializing happens are quite different. In the Multicultural Dinner, the focus is on talking over the meal and enjoying the entertainment together, whereas the Cooking Club socializes throughout the cooking and eating process. During the Multicultural Dinner, there was a clear divide between those who paid for the dinner, and thus ate in the decorated room with music, and those who prepared the dinner and sat out in the hallway, making the dinner a large production rather than a gathering of friends. However, this gathering, in contrast with the Cooking Club, could potentially facilitate interactions between people from different programs in the house.

During the Cooking Club meeting, the divide was more between people's different reasons for being there than what we did: between the members of the Cooking Club on the one hand, and, on the other, the staff and the volunteers (like me) who helped get the cooking process started but left the kitchen as more members showed up to take over. When the club meeting first started, I was part of the cooking crew, cutting vegetables and adding spices; as more people showed up, however, Brianna, my supervisor, asked me to leave the kitchen and help her with other parts of the event, like making name tags. She said that knowing when to draw back from an activity and leave it for the participants is an important part of giving participants a safe and fun space to be. As the staff withdrew, the kitchen became a place of laughter, spicy smells, and people talking about food and other parts of life.

The more congenial atmosphere of the Cooking Club could be a result of a club policy of trying to speak English as a common language, as well as of trying to get as many people involved with the cooking process as possible or of chatting with people sitting at the tables while the food was cooking. A common language makes it easier to get people involved, but only if they speak that language, which is one thing that made the Multicultural Dinner different. That evening there was no clear common language, so the group divided along linguistic lines as well as the lines drawn by the event organization itself. Although the dinner preparation included more people, it also alienated more people, at least on the volunteer end.

Thus the creation of social interactions in the neighborhood house contrasted with the unity depicted by Lees (2010) and the methods of taming space described by Robertson (2007), even if the goals were similar. The house is an institutional effort to facilitate the creation of social networks that in Lees' field site occurred more organically. Staff at the house seek to bring together and recognize the different strengths and roles of members through different activities (Lees 2010, 398) and must deal with a heterogeneous population (Lees $2010,393)$. The house, partially funded by the government and run by a board of wealthier area residents, is a highly programmed effort to mimic the type of face-to-face networking that can occur more organically in communities, like what Lees describes. However, such unintentional casual networking is difficult to create in an area undergoing major gentrification, when significant differences of class or lifestyle may divide the population. The house also gives people a place to see their friends and belong, similarly to how the DTES offers a place of belonging (Robertson 2007, 539). However, as Robertson discusses, there is also a desire to tame space for oneself or one's group (Robertson 2007, 544). The house was a site of a complex and ever-shifting web of social relations depending on the people and groups present. 
The governing factors of this web seemed to be language abilities and the will to establish a common language in a given activity, as well as people's purposes or reasons for going to the house. These aspects follow Goffman's assertion that "in so far as they [in this case, members of the neighborhood house] cooperate in maintaining a given impression, using this device as a means of achieving their ends, they constitute what has here been called a team" (Goffman 1959, 84.) If a person sought to be social, like the regulars who chat over coffee and come in several days a week, then that person's community of people to interact with encompassed others encountered in those situations. If a person saw the house as a place to do a certain activity or access a service like daycare, then that person saw only those in the narrowed field of focus around those services and events. The various social groups active within the neighborhood house depend, to some extent, on the members of those groups using the programs to achieve a certain end, whether it be socializing, cooking a meal, learning a language, or otherwise being socialized into the urban Canadian context. The two dinners discussed differed mainly in scope: the Cooking Club had fewer participants but had more flexibility in who could interact with whom; the Multicultural Dinner served more people but generated a narrower definition of who interacted with whom, limited by who shared a table in the dining room or a language in the kitchen. (Unfortunately, due to my position in the kitchen, I was not able to see how people chose which table to sit at and who to talk to.) Thus it is not just physical space and its functions, but also social and mental space and goals that determine how people interact and include others or not.

\section{An Administrator's Point of View}

During my time at the neighborhood house, I interviewed my supervisor, Brianna, about how she saw her position within the house as the Community Developer and where she wants the programming to go. She explained, "We work on those different spectrums of the community development. We go from service, to engagement, to empowerment." Thus my supervisor saw the house not just as a place where people would meet, but to have those meetings give people power and confidence in their own abilities such that they eventually feel more certain of their autonomy and agency. This was part of why the house relies heavily on members to act as volunteers to share their time and knowledge. If members put their own work into a project, like in the Cooking Club, they had something to show for it, a meal to share with friends, along with new or reaffirmed cooking abilities. The people leading programming at the house then sought to facilitate social and knowledge exchanges, developing social networks, and building a stronger sense of community in the process.

Specifically with regards to the Cooking Club, Brianna said, "It's a good way to feed your family. It's a good way to make friends. It's a good way to have more of a social experience. Because you could get really isolated." She contrasted this with the Multicultural Dinners by saying, "[the Multicultural Dinner is] more open just because there's a fee, it's easier right? And we have more space, like we take up to a hundred, maybe eighty people." The latter was also more widely advertised due to the larger space capacity. The Multicultural Dinner reached out to people across programs and even outside of the house, thanks to people inviting their friends, possibly creating furtherreaching social networks. The Cooking Club was smaller and focused on deepening in-house relationships, often formed in the settlement programs or between people who like socializing around food. Brianna realized this, noting, "The Multicultural Dinner is more sharing, like open sharing without necessarily getting too close. Yeah, and I would say the Cooking Club is about more like making friends because you actually get to relate to people more closer than, than the dinner."

Brianna's understanding of the differences between the two groups reflected the conclusions I reached about them, but is based on a different point of view. While she was talking about the house as a whole, my position in the kitchen gave me get a glimpse of how some of the volunteers, many of whom are members of the house, interact in these different contexts. I do not know if Brianna has seen or thought about these differences specifically as she did not mention them in the 
interview. However, based on volunteer comments, the programs were run differently in the kitchen and, based on my observations, the staff handling of these two events does not quite match up with Brianna's stated intention.

A volunteer during the Multicultural Dinner, who was also a member of the Cooking Club, tried to get more of the women to speak in English, saying that this would help include more people in the cooking process. The Multicultural Dinner did not have a rule about language use that members imposed and reinforced like the Cooking Club did. At neither event did a staff member comment on trying to speak a common language, suggesting that it was the members who thought that the rule was important enough to try and enforce. Again, this demonstrates how different groups within the house constituted Goffmanian teams. These teams depend on the ways that members deploy group identity characteristics by controlling their mask in a group performance. Goffman's idea of masks, "the role we are striving to live up to" (Goffman 1959, 19), encompasses how people try to act within a social interaction to follow established social rules and expectations. While the Multicultural Dinner did not have an overt rule about language use, there were clearly other social expectations at play in terms of how people interacted in the kitchen versus out where the entertainment and socializing was occurring. Even within the Cooking Club there were other clear means of mask control that governed how people interacted with each other. For example, people shared stories about where they were from, listened to the person leading the event, and so on. All such activities culminated in establishing an outwardly orderly event and coherent group interaction that reinforced elements of a group identity.

This instance is almost the opposite of what Stacey Pigg (2013) found in her work with international non-profits, where the language was too tightly controlled to be relevant to the people the organizations sought to help. Pigg argues that the NGOs she studied could not actually help the people in the area because the NGOs were not allowed to translate the language of the organization into the language of the local people. The wider organizations had too great a control over their members' actions and the organizations' self-presentation through pamphlets and language, and people within them were stuck trying to work through broken policies. In the case of the neighborhood house, it was instead the lack of language policies or suggestions that isolated different people. While English was the language of the Cooking Club, it made sense that it was not the lingua franca of all events, like the Chinese choir or Spanish parenting group. However, perhaps having a stated language policy for some events would help achieve the goal of empowerment in a mixed language environment. Of course, this would only address the question of how to communicate in an environment where people have already gathered to socialize with each other; it does not examine the complications of interpreting and understanding how people and the house are set up to socialize or not across different groups inside the house.

\section{Communities, Space, and Liminality}

The neighborhood house offered a variety of programs for people to bond over, creating communities of people where everyone could see each other. However, the community of people who identified as members also created imagined communities, which Benedict Anderson (1991) defines as "imagined because the members of even the smallest nation will never know most of their fellow members" (Anderson 1991, 6). Anderson is talking about nations, but such ideas can also apply to smaller numbers of people, since most members of the house do not regularly see each other but still identify as members of the same group, the neighborhood house. The members of the house also form a community by Anderson's definition because "in fact, all communities larger than primordial villages of face-to-face contact (and perhaps even these) are imagined" (Anderson 1991, 6). Thus the members of the house may belong to a variety of imagined communities because any group that considers itself a group might not physically see everyone thought to be in the group at a given time or activity, but still acts as a collective, and is thus an imagined community. 
These imagined communities exist on multiple levels, arising from connections on the Goffmanian teams created around the activities in which people participate. They also socialize limitations based on the languages people speak, the places they identify as coming from, the places they live, and so on. Thus, the divisions of the surrounding neighborhood area might also have been a function of imagined communities, where specific streets arbitrarily made up part of an identity from the accident of who ended up talking to whom. However, within the house, the divisions between groups and the cohesion of different groups were strong or weak to different degrees depending on the situation. Such variations are based on perceived aspects of team identity and what elements of personal masks facilitate or challenge the conception of a particular group identity. For instance, in a kitchen where there were women from different Spanish speaking countries, the women mentioned which countries they came from, but then fell into a single group by speaking a common language. This created a cohesive group of Spanish speakers while defining a boundary of who was not a part of it, by virtue of using a language that not everyone in the kitchen could speak.

This does not explain how the larger house events hailed a larger group identity that was pushed aside once the event is over in favor of smaller activity-based group identities. There was something special about the larger events that let people break through the smaller imagined communities that function on a daily basis, in order to focus on the larger community of membership in the house. Unlike the instances when daycare parents ignored the people sitting on the couches, or when the Chinese choir did not interact with the kids group next door, the Multicultural Dinner and the Cooking Club were liminal events. Liminality, for the purposes of this paper, is the idea that for short, defined periods of time, a new social or interactional order is created inbetween established orders. These events were in-between the daily social patterns, like who talked to whom while sitting in the couches on a given day, or who came in for coffee, because the coffee and couches were available any time the house was open, while the special events were transitory moments. Consequently, during these larger events, people developed a liminal persona, which Victor Turner (1967) describes as "invisible" because "the structural "invisibility" of liminal persona has a twofold character. They are no longer classified and not yet classified" (Turner 1967, 96). The larger events brought people from different subgroups within the house together and created an inbetween space where people could simultaneously inhabit multiple identities: one being the group(s) they were involved in within the house, the other belonging to the Cooking Club or the Multicultural Dinner. Neither identity encompassed the whole person, but rather influenced how people interacted in larger mediating social contexts that broke the patterns of normal socialization.

The idea of liminality in this context is further enhanced by Goffman's ideas of teams and how members express different elements of themselves through their social masks (Goffman 1959, 19) to facilitate group conformity (80). The context of liminal events like the Cooking Club and Multicultural Dinner gives participants a time-space area to engage in a group activity larger than other ones run by the neighborhood house, yielding a new group or "team" to be a part of. As such, the identifying characteristics of this team are different from those of other, smaller activities, and thus people's masks must change to foster their new social alignment.

This use of liminality differs from Van Gennep's, which considers liminality primarily in relation to sequential rites of passage: "Although a complete scheme of rites of passage typically includes preliminal rites (rites of separation), liminal rites (rites of transition), and postliminal rites (rites of incorporation), in specific instances these three types are not always equally important or equally elaborated." (Gennep 1960, 11). Instead of passing through a transitional series of rites at the larger social events, the people socialized in a temporary space that, at least for a while, transcended the subgroup memberships with which people aligned at other times in the house. The liminal spaces then also took on aspects of permanence by recurring at monthly intervals, despite the actual event only lasting for a few hours. 
The house staff could use these events to temporarily, but regularly, transcend the smaller imagined communities created by the different services and activities such as the daycare, free coffee, conversational groups, and choirs. When these events were not in session, people redefined themselves based on which group they were active in at a given moment. In other words, individuals' social masks were determined by the team that coalesced around the neighborhood house activity they spent the most time doing. These patterns of liminal activities determining temporary team identities did not just exist in the neighborhood house, but also in the larger community, which was apparent on my walks through the neighborhood. Outside the house, however, liminal spaces were defined more by physical space, like streets and yards, rather than the activities and room dividers that marked them out inside the house.

\section{Gentrification}

In the wider neighborhood, gentrification played a role in determining which physical spaces were used for socializing and what types of teams formed, as manifested in people's mask creation and maintenance. In places where people talked to their neighbors outside their own houses, it was perhaps because they had defined an imagined community around the concept of neighbors and the idea that neighbors should talk to each other. In my observations, however, some of the other streets were quieter and the residents did not spend much time outside talking to people who lived nearby. These observations of differences in social identity creation and maintenance follow the patterns of gentrification mentioned earlier (Saracino 2010, 13; Glass 2010, 21; Zukin 2010, 37; and most overtly Levy and Cybrivsky 2010). Thus, it comes down to how the newer residents who live in the freshly painted homes defined their identity with regards to the neighborhood. For some it might have just been a place to live; for others, it was a system of social networks.

The neighborhood house's liminal spaces formed around the boundaries of teams whose identity was based on an activity. These groups formed explicit teams, while other key groups were comprised of the people who used the house's services, like the daycare, but did not attend other house events. This latter group of people did not qualify as an explicit team because they had no set task to perform, other than using a particular service within the context of the house, but they nonetheless formed a visible group. The group's identity was based on consumption practices as part of gentrification (Glass 2010, 21), where the key to being part of the group was a Goffmanian mask created by using certain services in the house and wider lifestyle performances. This division became apparent while I was conducting surveys of people at neighborhood events in the area. For example, the neighborhood house had a booth at a local school fair. People whose children went to the school came because it was a fundraiser for the area and to visit other booths that listed local services. While I was there, I conducted surveys to see what people outside of the house would want from the house or whether they had been there. During this time, I met an older white man with white hair who had served on the board of directors for the house, who said nothing about how long he had lived in the area, but said he never really attended events or used any of the services. He was not the only one. A young white man in his 30s told me, when I asked him if he knew of the house, that he was really only interested in getting his child into the daycare or preschool, and expressed no interest in any of the other activities the staff ran. His conception of group identity with regards to the house solely followed the activity of consumption and performing a wider group identity through such associations. If Goffman's idea about "staging a single routine" is broadened to include commodity consumption, than this group would also qualify as a "team," but in a much wider context and scope.

These responses from outside of the house show a clear division between existing residents and some of the people newer to the area, as well as possible class and racial divides. The newer, wealthier, typically white families moving into the area could change how the house works and who can access its services. While I was there, the programming was heavily focused on helping people who had recently immigrated into Canada, and/or had linguistic 
or cultural differences from the imagined community of Canada at large. However, as my walk through the neighborhood showed, the diversity of the area is changing: rents are rising, and the younger, wealthier families who are moving in could be pushing out some of the lower-income recent immigrants from the area. This means that some of the people who could use the services offered by the house travel long distances to it via public transportation or other methods, while the people who live closest to the house use the fewest number and narrowest range of the house's programs.

These families, the ones using the daycare and preschool, may socialize outside of the house, thus forming an imagined community through their consumption of a program at the house, but functionally operating outside of it. It could also be that the parents of these children do not interact with each other at all, except to pick up and drop off their kids; I do not know as I was not able to be involved in either the preschool or the daycare. It would be an area for further study and could indicate how the programming at the house may need to change in order to serve the people in the Mountain area.

Parents or guardians need the services of a daycare or preschool for longer than a single night, but their use of the house mirrors the patterns of some of the weekly events at the neighborhood house. The choirs and conversation groups may not make much use of all of the events at the house either, so perhaps the parents in the area are not all that different from other members of the house. Instead, perhaps the house simply served as a location rather than a liminal event conducive to meeting people outside of an established social group. What changes with gentrification, though, is how far people who are targeted by many of the services offered at the house especially newcomers to Canada - will have to travel to use them. That said, events like the Multicultural Dinner do not happen very often, lessening the inconvenience of traveling further to participate in them. As the process of gentrification continues, I wonder how far people will need to move in order to afford to live comfortably, and how long they will still use the Mountain neighborhood house as opposed to others in the Vancouver area.

The conflicting identities of teams created at the neighborhood house show how liminality and imagined communities are part of what creates Goffmanian regions. Some regional barriers can be physical - the way that certain areas of the neighborhood are heavily fenced or controlled by community police - while others are socially constructed- who is allowed to what events and who converses with whom. Gentrification in the Mountain area is creating perception barriers based on consumption practices - whose children get into the daycare, who goes to the Multicultural Dinners, and who can afford to live in which houses. Money and the curation of particular neighborhood images erase marginal people from the image of the area. Even though many lower-income people and recent immigrants still live in the area, the stores popping up recently as well as the patterns of socializing amongst wealthier newcomers cultivate a different image for the future of the neighborhood. The newer image of the Mountain area is based on perceived ideas of social progress through the monetary investment seen in new houses and new stores (Zukin 2010), and as various parts of cities compete for such redevelopment (Atkinson and Bridge 2010, 59), gentrification is encouraged by city development projects and changes in the real estate market. The Mountain neighborhood image is ripe for revision, as Vancouver's focus on sociocultural fields (Ley $2010,106)$ only encourages the illusion of la vie bohème associated with redevelopment in gentrifying areas (Mele 2010, Atkinson and Bridge 2010, Lloyd 2010, Glass, 2010, Smith 2010).

The Mountain Neighborhood House's response contrasts with the outcry over the situation in Strathcona, as described by Lee (2007), in that residents in the house never expressed any concern for the changing situation in the neighborhood and certainly did not mention being upset by the divisions within the house programming. This suggests, again, that perhaps the members of the house are not worried by the changing face of the neighborhood. Maybe the events within the house offer enough stability and people are able to commute to them easily enough that 
larger events are not really threatened by the changing times and demographic makeup. The gentrification process only continues, however, and as it does so, it will probably affect the neighborhood house at some point, but not in any clear, single way. As shown in the housing report for the Downtown Eastside (Sutherland et al. 2014), there is a growing housing crisis in Vancouver with a clear lack of affordable housing, leading to greater social stratification within the city. Rising housing prices force more people to either move or face financial struggles by staying in the same area. Robertson (2007) discusses how important access to services is to feeling at home and safe in an area, but the question of which services and who they will be helping remains to be settled. Currently the Mountain Neighborhood House still offers a diverse array of services, and Brianna mentioned wanting it to stay that way in the interview. She also wanted to help poorer parts of the community by offering programs with even lower food prices, showing her desire to reach out to lower-income people moving into the Mountain area as they get pushed out of the Downtown Eastside and elsewhere. She did not mention expanding programs for the newer wealthier people in the area, perhaps because they do not need the house programs as much as those who are limited by money or language barriers.

While it is admirable that the house is reaching out to those mainstream society frequently forgets, I do wonder how the conception of what it means to be a member of the house will change depending on which developmental direction the house pursues. They can reach out to the newer residents of the area, who are largely wealthy and mostly seek the child-care services, or they can continue to reach out to more marginalized social groups who use the Multicultural Dinners and other programs to meet people in the area. The larger events could still serve as "liminal" bridges, helping people meet individuals from other groups within the house to foster a larger sense of imagined community, but only if people want to develop a broader team orientation. The people who openly identify as members of the house tend to be those who use the larger programs and meet the largest diversity of people. Those who use only a few programs keep to themselves and their smaller imagined communities, possibly creating future barriers within the neighborhood house, whose programs cannot continue to diversify without community support and funding. The effects of gentrification appear to be only starting to be felt at the house, as new people seek it out only for its physical services and not the social ones. Further research over a longer period of time could investigate how the house, and its members, perceive and react to the changes if they continue.

\section{Conclusion}

The neighborhood house created a middle ground between individual people and the idea of the neighborhood at large. It mirrored the divisions of the neighborhood at large via different methods of identity and community creation, but also gave people the chance to transcend the boundaries of imagined communities. However, it was not a completely open environment, either through accident, manipulation, or ease of use. The choice of a lingua franca, for instance, was partially an accident - people started talking in a language they knew they shared, and people who joined tried to follow the established pattern, perhaps explaining how Spanish became the lingua franca during the Multicultural Dinner. In other instances, the house staff or the members have a stated language policy, deliberately manipulating the choice of language with the intention of easing communication and allowing team formation.

Gentrification is changing the Goffmanian regions of the area by introducing new teams who engage in different primary or consumption activities and thereby inhabit different masks in interpersonal interactions. My walk around the area before my fieldwork started shows how gentrification creates visible regions whose barriers are higher priced stores and a particular idea of society entwined with rebellion against previous urban/suburban ideologies (Smith 1979, 72; Smith 1998, 35; Zukin 1982; Ley 1996). These areas are inhabited by wealthier, younger, often white, residents, while the older areas are more racially diverse and lower-income, with multigenerational households. These different lifestyles and life stages interact with the wider 
area in different ways, through patterns of participation in activities or consumption, thereby creating teams with other individuals and/or families who participate or consume similarly. Such regional and team identities, influenced by life outside of the house, are mirrored in interactions within the neighborhood house.

Imagined communities, or teams with a set activity or pattern of behavior, exist within the neighborhood house and serve a socializing function, regardless of language, due to their liminality. During an activity, people are given the opportunity to meet people from different programs and, through the course of the activity, reorient to new team identities through shared projects. Perhaps through the regularity of the liminal activities, it is possible for members to make friends and form new imagined communities, crossing group divides. Such communities and boundaries almost always exist within social and physical spaces, either feeding off or creating further boundaries between people, but also generating aspects of identity. When one is a member of a group, one simultaneously makes oneself separate from a larger population and yet unified with a subset, in ways that are often identifiable by others.

Gentrification could fundamentally change the neighborhood house as it will inevitably change the surrounding Mountain area, but it could also offer opportunities for community creation and understanding. If the house staff manages to increase the diversity of its programs, as well as encouraging all to participate in the larger events, then these events could offer additional liminal spaces for people of different classes and backgrounds to meet. These meetings could then benefit the community at large by fostering a better understanding of the diversity among members of the house, but only if the newer users of the house's services decide to break out of their established patterns and attend such events. It all depends on how people define and perceive their neighbors. Is "neighbor" a category that extends beyond physical, social, and cultural boundaries, or is it doomed to be defined by them? The next few years should tell.
Liminal events invite people to complicate or add to their identity by minimizing previous team identities via new teams created by a shared orienting activity or purpose. Perhaps by understanding how the different levels of imagined communities operate it might be possible to better understand ourselves and how we choose to define ourselves and interact with others. Maybe we can take this information and challenge ourselves to talk to people we would not have otherwise; we never know what we might learn and this knowledge can empower us or others to do more for our neighbors and neighborhoods and to have a better sense of what our neighborhood is and with whom we share it. 


\section{References}

Anderson, Benedict R. 1983. Imagined Communities. London: Verso.

Atkinson R. and G. Bridge. 2010. “Globalization and the New Urban Colonialism." In The Gentrification Debates, edited by Japonica Brown-Saracino, 51-61. New York: Routledge.

Glass, Ruth. 2010. "Introduction: Aspect of Change." In The Gentrification Debates, edited byjaponica Brown-Saracino, 19-29. New York: Routledge.

Goffman, Erving. 1959. The Presentation of Self in Everyday Life. New York: Doubleday Anchor Books.

Hamnett, Chris. 2003. "Gentrification, Postindustrialism, and Industrial and Occupational Restructuring in Global Cities." In $A$ Companion to the City, edited by Gary Bridge and Sophie Watson, 331-341. Malden, MA: Blackwell.

Ho, Selena. 2015. "How Welcoming Space is Created, Maintained, and Always Evolving in Frog Hollow Neighbourhood House." The Journal for Undergraduate Ethnography 5(2): 29-39.

Lee, Jo-Anne. 2007. "Gender, Ethnicity, and Hybrid Forms of Community-Based Urban Activism in Vancouver, 1957-78: The Strathcona Story Revisited." Gender, Place and Culture 14(4): 381407.

Lees, Loretta. 2010 "Super-gentrification: The Case of Brooklyn Heights, New York City." In The Gentrification Debates, edited by Japonica Brown-Saracino, 45-50. New York: Routledge.

Levy, Paul. R. and Roman. A. Cybriwksy. 2010. “The Hidden Dimensions of Culture and Class: Philadelphia." In The Gentrification Debates, edited by Japonica Brown-Saracino, 285293. New York: Routledge.

Ley, David. 2010."Introduction: Restructuring and Dislocations." In The Gentrification Debates, edited by Japonica Brown-Saracino, 103-112. New York: Routledge.

Lloyd, Richard. 2010. "Living Like an Artist." In The Gentrification Debates, edited by Japonica Brown-Saracino, 185-193. New York: Routledge. 
Mele, Christopher. 2010. "Forging the Link between Culture and Real Estate: Urban Policy and Real Estate Development." In The Gentrification Debates, edited by Japonica Brown-Saracino, 127132. New York: Routledge.

Perez, Gina M. 2010. “Gentrification, Intrametropolitan Migration, and the Politics of Place." In The Gentrification Debates, edited by Japonica Brown-Saracino, 319-329. New York: Routledge.

Pigg, Stacey Leigh. 2013. “On Sitting and Doing: Ethnography as Action in Global Health." Social Science and Medicine 99: 127-34.

Robertson, Leslie. 2007. "Taming Space: Drug Use, HIV, and Homemaking in Downtown Eastside Vancouver." Gender, Place and Culture 14(5): 527-49.

Smith, Neil. 2010. "A Short History of Gentrification." In The Gentrification Debates, edited by Japonica Brown-Saracino, 31-37. New York: Routledge.

Sutherland, Rory, Jean Swanson, and Tamara Herman. 2014. No Place to Go: Losing Affordable Housing \& Community. Carnegie Community Action Project's 2013 Hotel Survey and Housing Report. Vancouver: Carnegie Community Centre Association.

Turner, Victor W. 1967. The Forest of Symbols: Aspects of Ndembu Rituals. Ithaca, NY: Cornell University Press.

Zukin, Sharon. 2010. "Gentrification as Market and Place." In The Gentrification Debates, edited by Japonica Brown-Saracino, 37-44. New York: Routledge. 